\title{
The Effects of the Multimedia, Modality, and Redundancy Principles in a Computer- Based Environment on Adult Learners
}

Ray Pastore

Associate Professor of Instructional Technology

University of North Carolina Wilmington, 601 S. College Rd.

Wilmington NC, 28403, US

rayme.pastore@gmail.com

Tutaleni I. Asino

Assistant Professor, Educational Technology, School of Educational Studies

Oklahoma State University College of Education

209 Willard Hall, Stillwater, OK 74078, US

tutaleni.asino@okstate.edu

Jessica Briskin

Assistant Professor of Instructional Technology

Bloomsburg University of Pennsylvania, US

jessica.briskin@gmail.com

ABSTRACT: Computer-based training (CBT) has become a common form of instructional delivery in business and educational environments. A standard practice during the design and development of CBT, is to incorporate the multimedia principle to aid learning. However, a recent meta-analysis by Pastore, Briskin, and Asino (2016) revealed that very little research has actually examined the multimedia principle (single vs. multiple representations) on adult learners in a computer-based environment. Instead, much of the research has focused on K-12, used paper and pencil rather than a computer, did not compare single vs multiple representations, or had methodological issues (i.e. did not report the type of knowledge assessed). As a result, the current study examines the multimedia, modality, and redundancy principles in a computer-based environment with adult learners on learning (high-and low-level knowledge) and cognitive load measures. The results of the low (recall) and high (transfer) level learning tasks in this study supported the multimedia principle. Multiple representations were found to better support learning than just one. However, this was not the case for modality or redundancy principles. Learners presented duplicate text and narration or text with optional narration performed just as well as those with no duplication, indicating reverse redundancy. Additionally, the narration and images groups did not outperform text and image groups.

Keywords: Multimedia Principle, Multimedia, Multiple Representations, Redundancy Principle, Modality Principle

Received: 22 December 2018, Revised 5 March 2019, Accepted 3 April 2019

DOI: $10.6025 / \mathrm{jmpt} / 2019 / 10 / 2 / 49-61$

(C) 2019 DLINE. All Rights Reserved 


\section{Introduction}

It is easy to define multimedia as meaning multiple media; however, that is overly simplistic and misses the richness of the origin of the word and the fields it traverses. Although the word is indeed a concatenation of multi (many) and media (plural of mediuma means of doing something), it has a long history that Packer and Jordan (2002) argue was advanced and popularized in the 1960 s by the performing arts and entertainment industries. While it can be argued that newspapers were the early adopters of modern multimedia through the use of text, graphics, and images, the current manifestation of digital multimedia is heavily linked to the mass production of the personal computer in the late 1980s. This is reflected in Vaughan's (2011) definition of multimedia as "a woven combination of digitally manipulated text, photographs, graphic art, sound, animation, and video elements" (pg. 1).

Today, our understanding of what is a computing device has evolved from large desktop machines to handheld devices. Consequently, the consumption of multimedia has taken on a near-ubiquitous presence in our lives. In education related scholarship, educational psychologist Richard E. Mayer has written prolifically on the use of multimedia or what he has termed multimedia learning. Mayer (2005) asserts that multimedia learning is the bringing together of verbal and nonverbal representations that support learning and / or communication. His research along with various decades of research on multimedia learning has yielded multimedia principles which serve as guides in the creation of multimedia designs in education.

Multimedia principles are significant especially in the design and development process because they can guide designers to improve learning by decreasing the cognitive load on working memory (Mayer, 2001; Gunawardhana and Palaniappan, 2016; McAlpin, Kalaycioglu, \& Shilane, 2019). Moreno and Mayer (2002) argued that the creation of multimedia learning environments enables learners to build their own models by experiencing and coordinating multiple knowledge representations. Integral to the multimedia principle is the belief that one is able to learn better from a combination of media. For example, learning is improved when pictures (non-verbal) and words (verbal) are used together (Rapchak, 2017; Mayer, 2014; Eitel, Scheiter, \& Schuler 2013; Sung \& Mayer, 2012; Clark \& Mayer 2011; Issa, Schuller, Santacaterina, Shapiro, Wang, Mayer \& DaRosa, 2011; Pastore, 2010).

Multimedia learning can be likened to the idiom walk and chew gum at the same time. The similarity here is the idea that it is possible for an individual to do more than one thing at once. In other words, research on multimedia learning is anchored in a belief that human beings are capable of using multiple modes to experience the world such as engaging difference senses to hear the thunder and see the lightning (Mayer, 2001). Today's multimedia learning environment can at best be described as ranging from static to varied immersive computer-mediated realities. As a result of this, it is no wonder that multimedia is popular in professional environments.

With the growth of on-the-go training, computer-based instruction has helped fill a need for many practitioners in business and educational environments (Reyna, Hanham, and Meier, 2018). Thus, one would assume that there is a plethora of research examining the multimedia principle in these environments; however, a recent meta-analysis by Pastore, Briskin, and Asino (2016) revealed, there is very little research comparing single vs. multiple representations in a computer-based training environment with adult learners. Instead, much of the research has focused on K-12, used paper and pencil rather than a computer, did not compare single vs multiple representations, or had methodological issues (i.e. did not report the type of knowledge assessed). As a result, more research on how to effectively design multimedia instructional is needed to improve learning in this environment.

\section{Literature Review}

\subsection{Multimedia}

The advancement in computing combined with the reduced cost of devices over time has led to a diffusion (Rogers, 2010) of computing devices that can accommodate multimedia presentation. This has opened up new ways for designers to create engaging and attention-grabbing learning content and environments for learners. However just as the liberal uses of visual and auditory modes can be exciting for the learner and designer, it can also be counterproductive to the learning process (Sorden, 2005).

Substantiated by a significant body of research spanning more than two decades (Mayer, Bove, Bryman, Mars, \& Tapangco, 1996, Mayer 2002, Nagmoti, 2017), the multimedia principle promulgates the notion that students learn better from words and images rather than from words alone. Presenting pictures and words permits students the opportunity to build verbal and pictorial mental models and to create connections between them. Adversely, when presenting words alone students are less likely to achieve the same objective (i.e. build a pictorial mental model and make connections between verbal and pictorial mental

Journal of Multimedia Processing and Technologies Volume 10 Number 2 June 2019


model). Put differently, "learning and understanding are enhanced by adding pictures to text rather than presenting text alone" (Clark \& Mayer, 2011, p. 81).

For more than half a century, researchers have theorized about the human mind's limited ability to store and process information. According to Miller (1956), the mind can store seven units of information, plus or minus two, in our working memory at one time without exceeding cognitive capacity. This initial research explains that there is limited capacity in working memory and that exceeding this capacity leads to depressed learning (Brünken et al., 2003). This load placed on working memory when processing these units is referred to as cognitive load (Chandler \& Sweller, 1991).

Australian educational psychologist John Sweller $(1988 ; 1994)$, formulated the cognitive load theory, which argues that human memory, consisting of both long term and working memory is limited in terms of the information it can process. As Cooper (1998) explains, "Cognitive load refers to the total amount of mental activity imposed on working memory at an instance in time" (pg 11). A major contributor to cognitive load is the number of things that the mind has to attend to at once. As Cooper further explains, remembering 2 or four numbers is much easier than remembering 8 or 16 digits. Hence the mind can be overloaded with information the more elements it has to remember or process. Cognitive load theory is commonly referenced as a supportive theory for creating effective instructional design.

Cognitive load is comprised of three types of which are described as extraneous, intrinsic, and germane (Sweller, Van Merrienboer, \& Paas, 1998). The following descriptions of the three types of load are adapted from Mayer (2014): Extraneous load is that of design. Thus, utilizing design principles aimed at reducing extraneous load increases learning. This type of load is being manipulated in this experiment through the multimedia, modality, and redundancy principles which are described further in this paper. Intrinsic load is affected by the material difficulty (element interactivity). Finally, the germane load is the load that leads to schema construction.

As noted earlier, the multimedia principle is predicated on the notion that people learn better from words and images than from words alone. Early research on multimedia learning was based on text combined with still or animated images. For example, Hegarty and Just (1993) compared learning materials that consisted of text, diagrams, or a combination of both. However as computing technologies continue to develop, the principle is applied more broadly and incorporated various visual and auditory representations (Butcher, 2014). This principle speaks to facilitating mental connections between words and images through the uses of dual-channel processing. The multimedia principle is further supported by a number of theories including cognitive load theory, information processing, cognitive load theory, and dual coding (Mayer \& Moreno, 2003; Sweller, 1999; Baddeley, 1998; Paivio, 1986).

The overreliance on multimedia as tool for facilitating learning has produced a significant body of research around the multimedia principle (e.g. Hegarty and Just,1993; Bove, Bryman, Mars, \& Tapangco, 1996; ChanLin, 2001; Pastore, 2010; Issa, Mayer, Schuller, Wang, Shapiro, and DaRosa, 2013; Chen and Yen, 2019). Pastore, Briskin, and Asino (2016) conducted a meta-analysis aimed at examining the effects of the multimedia principle on Computer Based Training (CBT). The focus of the study was to examine single vs. multiple representations, on different levels of learning (low-rate and high-meaningful knowledge). Overall, the findings revealed a difference in learner achievement when they are presented with single vs. multiple representations. Their finding also revealed a dearth of studies involving adult learners and CBT. While much of the principal's research focuses on the design of multimedia, they found very little focus on its application to computer-based instruction. As a result, this study attempts to examine the multimedia principle in a computer-based instruction environment while also exploring the effects of modality and redundancy.

\subsection{Modality and Split Attention}

The split-attention principle explains that when learners need to split their visual attention between on-screen text and images, that explain one another, working memory quickly becomes overloaded and inhibits learning (Mayer, Heiser, \& Lonn, 2001). This is referred to as representation holding (Sweller, Ayres, and Kalyuga, 2011), which refers to cognitive processes aimed at holding a mental representation in working memory over a period of time. By presenting information in two sensory modalities (visual and auditory) working memory can better handle the information (Mayer \& Anderson 1992; Tabbers, Martens, \& Van Merriënboer, 2000). As a result of this, the modality principle was born. The modality principle suggests that presenting verbal audio to complement images offsets this additional burden on working memory, caused by text, and can further increase learning (Low \& Sweller, 2005). The underlying concept is that on-screen text should be presented in an auditory form. Learners are able to focus 
on both representations (text and visual representation) at the same time without needing to split their attention between the text and visual representation.

A number of studies (e.g., Scheiter et al. 2014; Pastore 2012; Fiorella, Vogel-Walcutt, and Schatz, 2012) have confirmed the premise of both these principles. Florax and Ploetzner (2010) investigated the split-attention principle by using text segmentation and picture labeling. The results showed that participants who received spatially integrated text and pictures were more successful than participants who received continuous text (i.e., text not in bullets or numbered text format) and unlabeled picture (Florax \& Ploetzner, 2010). Additionally, Ginns (2006) conducted a meta-analysis of 43 studies, which showed that audio and visual representations were better for learning than text and visual. Fiorella, Vogel-Walcutt, and Schatz (2012) then confirmed these findings in their study of 60 participants with treatment consisting of either visual with narration, visual with printed text, or visual with no text or narration. The results showed that on low and high-level comprehension tests participants in the visual and narration treatments scored significantly higher than those who received the other conditions.

\subsection{Redundancy Principle}

The redundancy principle states that individuals learn better from graphics and text (or narration) than from graphics, narration and on-screen text presented simultaneously (Mayer, 2001). In other words, learners are unable to understand the information when they are trying to read, listen, and watch images at the same time. Kalyuga, Chandler, and Sweller (2004) further discuss how presenting both text and narration to the learner at the same time overloads their verbal processing channel and causes a decrease in learning. This happens in two ways: (1) "the visual channel can become overloaded by having to visually scan between pictures and on-screen text", and (2) "learners expend mental effort in trying to compare the incoming streams of printed and spoken text” (Mayer, 2009, p. 118).

For example, Pastore (2012) presented 154 university students with a treatment that included redundant text and narration with images, or narration with images. Participants who received the narration with images condition scored significantly higher on the problem-solving measure than participants in the redundant groups. Similarly, Yue, Bjork, and Bjork (2013) conducted two experiments where participants scored significantly lower on achievement tests when presented with redundant representations. Thus the redundancy principle has shown that presenting duplicate representations can hinder learning.

On the other hand, recent findings have had an important modification to the redundancy effect: reverse redundancy. Current literature (Koning, Hooijdonk, \& Lagerwerf 2017; Leslie, Low, Jin, \& Sweller, 2012; Mayer \& Johnson, 2008; Samur, 2012) shows a reverse redundancy effect in instances of multimedia instruction. This is when learners are presented with redundant, explanatory on-screen text along with spoken text that facilitated learning. For example, Mayer and Johnson (2008) found that when students experienced redundant on-screen text with related visuals and audio narration, their performance on retention tests were higher with on-screen text that is short and explanatory. Although there are many studies looking at the redundancy effect in multimedia instruction, results seem to be inconsistent (Ari et al., 2014). As Mayer (2009) discusses there is little research on whether the redundancy or reverse redundancy effects are true when learners control the pace of the instruction in complex, interactive multimedia instruction (Mayer, 2009). Further research needs to be done in this area.

\subsection{Purpose}

The purpose of this research study is to examine the effects of the multimedia, redundancy, and modality principles in a computer-based environment on recall, transfer, and cognitive load with adult learners. The results of this experiment will add to the literature base on multimedia and help to inform instructional designers creating computer-based training for adult learners.

\section{Methods}

\subsection{Participants}

A total of 145 university students participated in this study. These students were all undergraduate education majors from a midsized university in the United States. Participants consisted of 35 males and 110 females who ranged in age from 18-39. 134 participants were 18-22 years old, 9 were 23-30 years old, and 2 were 31-39 years old. Participants were native English speakers.

\subsection{Materials}

\subsubsection{Instruction}

The material used in this experiment was originally developed by Dwyer (1965) and later revised by Dwyer and Lamberski (1983). The content consisted of a 2,000-word script with 19 static simple line drawings on the human heart and its parts. The drawings

52 Journal of Multimedia Processing and Technologies Volume 10 Number 2 June 2019


contain color-coded shading to highlight the concepts being discussed on each slide.

\subsubsection{Prior Knowledge Pretest}

The pretest measured students' general factual understanding of physiology and was developed by Dwyer (1972). The test was modified from its original 36 questions to 20 questions for this experiment in order to cut down on test fatigue (Ackerman and Kanfer, 2009) and was used to ensure that participants' prior knowledge was equivalent across the treatments.

\subsubsection{Knowledge Posttests}

The knowledge posttests were designed with the instruction described previously by Dwyer (1965). The original instruction consisted of four tests: drawing, identification, terminology, and comprehension. However, for this experiment, only the identification and comprehension tests were used which measure recall and transfer. Dwyer (1978) determined the reliability of these tests by analyzing over 100 experimental studies to produce a KR-20 of .81 identification and . 70 comprehension.

Each test consists of 20 multiple choice questions. Dwyer (1978, pp. 45-47) explains that the identification test measures recall of factual knowledge and the comprehension test measures transfer of problem-solving. The identification test provides participants with a diagram of the heart and asks them to identify each position. The comprehension test requires a deep understanding of the material in order to correctly answer the questions.

\subsubsection{Cognitive Load Measure}

Cognitive load was measured via a 7-point Likert scale question which asked participants how easy or difficult the material was to understand (how much mental effort was required). While this is a self-report subjective measure, it has is been successfully used in multiple experiments to measure participants mental effort (Anmarkrud, Anderson, and Brataen 2019; Pastore, 2010; Kalyuga et al. 1999; Mayer and Chandler 2001; Pollock et al. 2002).

\subsubsection{Development of Instruction}

The computer-based training was developed by a professional instructional designer in order to ensure the quality of the presentation was using the latest principles of interface design to ensure the focus was on the multimedia principles being examined (Mahdi, Naidu, and Kurian, 2019; Kamaruddin and Sulaiman, 2018). Articulate software was used to develop the treatments. The instruction was set up so that the text/narration that corresponded to the image was presented with it on a screen. There was a total of 21 screens, which included directions on how to use the tutorial and ending slide with directions to take the assessment, and 19 screens which each contained an image (if an image treatment) and text or audio (see descriptions of treatments in section 3.3). Each screen also contained a next button for the user to go to the next slide. The audio was recorded by a professional male narrator.

\subsection{Treatments}

The study analyzed the following six conditions: text only, narration only, text and images, narration and images, text and narration with images, and text and images with optional narration. The text only $(T O)$ condition included only the script. The narration only $(N O)$ condition included only the audio narration. The text and images $(T I)$ condition included static images and the script. The narration and images $(N I)$ condition included the narration and static images. The text and narration with images $(T N I)$ condition included the script with duplicate narration and the static images. Finally, the text and images with optional narration $(T I O)$ condition included the script with optional narration that users could turn on/off (default was off) and static images.

\subsection{Procedure}

The study was conducted in a computer lab. Participants were provided headphones (if needed), a computer, mouse, and keyboard. The study was delivered via survey monkey, which included links to the computer-based training tutorials. The conditions were distributed to participants randomly. Participants began by taking the pretest, going through the computerbased instruction treatment, then taking posttests. The cognitive load measure was taken immediately following the instruction prior to the posttests.

\section{Results}

A series of ANOVAs were conducted to analyze measures of prior knowledge, recall, transfer, and cognitive load. Before conducting the ANOVAs, assumptions of normality, homogeneity of variance, and independent observations were satisfied 
(Hoekstra, Kiers, and Johnson, 2012). Prior knowledge was then examined to determine if there were differences among groups. There were no statistical differences in prior knowledge among groups $F(5,139)=.51, p=.769$, thus, tests for recall, transfer, and cognitive load were conducted.

\subsection{Results of the recall measure:}

Descriptive statistics for the recall measure are displayed in Table 1. The results of the recall measure, displayed in Table 2 and Figure 1, revealed a significant difference $F(5,139)=5.87, p<.001$, eta squared .18 . Tukey's post hoc analysis revealed that the TO $(M=9.36, S D 3.32)$ group scored significantly lower than the $T I(M=13.12, S D=3.29), N I(M=12.09, S D=3.24)$, and $T N I(M$ $=12.96, S D=2.53)$ groups. The $N O(M=9.91, S D=2.90)$ group scored significantly lower than the $T I(M=13.12, S D=3.29)$ and $T N I(M=12.96, S D=2.53)$ groups. The $T I(M=13.12, S D=3.29), N I(M=12.09, S D=3.24), T N I(M=12.96, S D=2.53)$, and $T I O$ $(M=11.80, S D=3.59)$ groups did not significantly differ from one another. The $T O(M=9.36, S D=3.32)$ and $N O(M=9.91, S D$ $=2.90$ ) groups did not significantly different from one another.

\begin{tabular}{|l|l|c|}
\hline & Mean & Standard Deviation \\
\hline Text Only $(T O)$ & $9.36(47 \%)$ & 3.32 \\
\hline Narration Only $(N O)$ & $9.91(50 \%)$ & 2.90 \\
\hline Text and Images $(T I)$ & $13.12(66 \%)$ & 3.29 \\
\hline Narration and Images $(N I)$ & $12.09(60 \%)$ & 3.24 \\
\hline Text and narration with images $(T N I)$ & $12.96(65 \%)$ & 2.53 \\
\hline Text and Images with optional narration $(T I O)$ & $11.80(59 \%)$ & 3.59 \\
\hline
\end{tabular}

Table 1. Descriptive statistics for recall measure

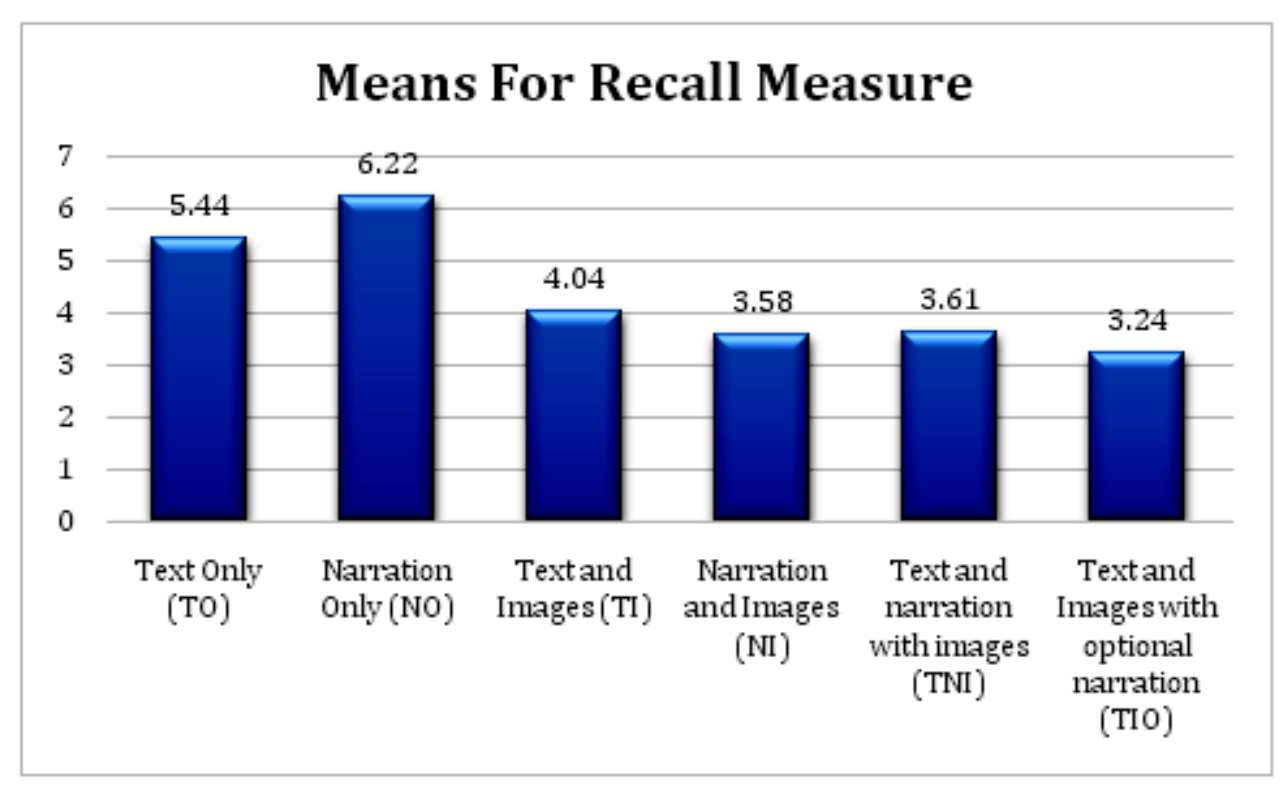

Figure 1. Means for Recall Measure

\subsection{Results of the Transfer Measure}

Descriptive statistics for the transfer measure are displayed in Table 3. The results of the transfer measure, displayed in Table 4 and Figure 2, revealed a significant difference $F(5,139)=6.671, p<.001$, eta squared .19 . Tukey's post hoc analysis revealed that the $T O(M=6, S D=2.06)$ group scored significantly lower than the $T I(M=9.26, S D=3.5), N I(M=8.21, S D=2.87), T N I(M=8.39$, $S D=2.4)$, and $T I O(M=8.4, S D=2.3)$ groups. The $N O(M=5.96, S D=2.07)$ group scored significantly lower than the $T I(M=9.26$,

54 Journal of Multimedia Processing and Technologies Volume 10 Number 2 June 2019


$S D=3.5), N I(M=8.21, S D=2.87), T N I(M=8.39, S D=2.4)$, and $T I O(M=8.4, S D=2.3)$ groups. The $T I(M=9.26, S D=3.5), N I$ $(M=8.21, S D=2.87), T N I(M=8.39, S D=2.4)$, and $T I O(M=8.4, S D=2.3)$ groups did not significantly differ from one another. The $T O(M=6.00, S D=2.06)$ and $N O(M=5.96, S D=2.07)$ did not significantly different from one another.

\begin{tabular}{|l|l|c|c|c|c|c|}
\hline \multicolumn{2}{|l|}{} & Sum of Squares & df & Mean Square & $\boldsymbol{F}$ & Sig \\
\hline Recall & Between Groups & 296.82 & 5 & 59.36 & 5.87 & .000 \\
\hline & Within Groups & 1395 & 139 & 10.11 & & \\
\hline & Total & 1691.83 & 143 & & & \\
\hline
\end{tabular}

Table 2. Recall ANOVA results

\begin{tabular}{|l|l|c|}
\hline & Mean & Standard Deviation \\
\hline Text Only $(T O)$ & $6.00(30 \%)$ & 2.06 \\
\hline Narration Only $(N O)$ & $5.96(30 \%)$ & 2.07 \\
\hline Text and Images $(T I)$ & $9.16(46 \%)$ & 3.50 \\
\hline Narration and Images $(N I)$ & $8.21(41 \%)$ & 2.87 \\
\hline Text and narration with images $(T N I)$ & $8.39(42 \%)$ & 2.40 \\
\hline Text and Images with optional narration $(T I O)$ & $8.40(42 \%)$ & 2.30 \\
\hline
\end{tabular}

Table 3. Descriptive statistics for transfer measure

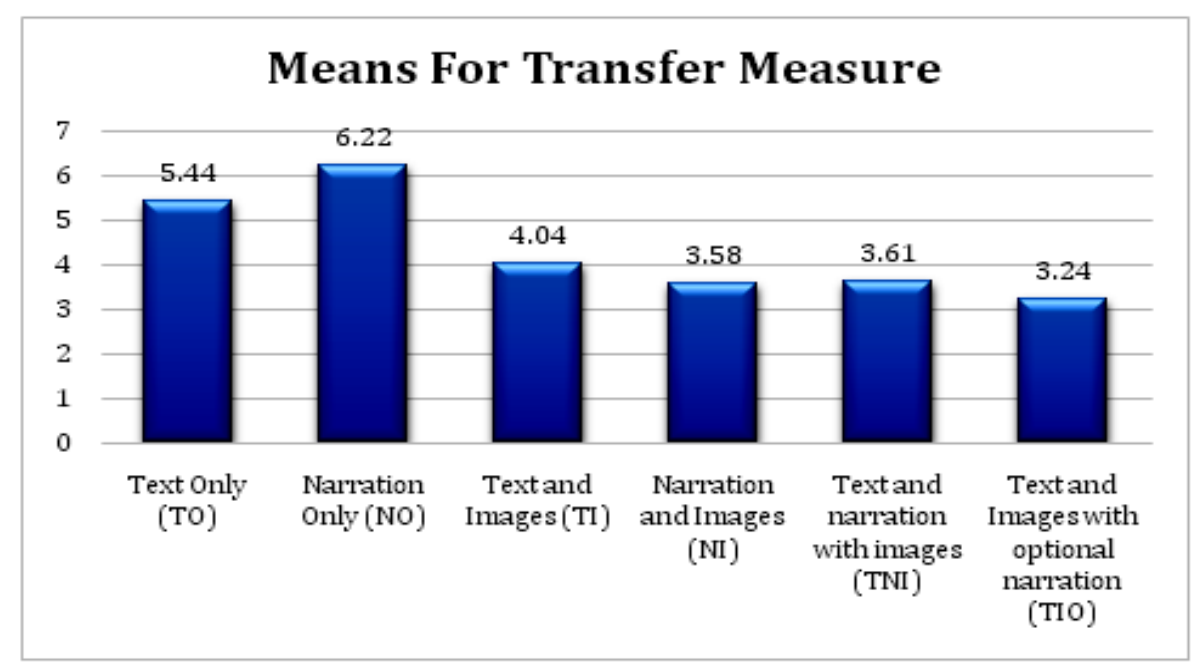

Figure 2. Means for Transfer Measure

\begin{tabular}{|l|l|c|c|c|c|c|}
\hline & & Sum of Squares & df & Mean Square & $\boldsymbol{F}$ & Sig \\
\hline Transfer & Between Groups & 224.89 & 5 & 44.98 & 6.67 & .000 \\
\hline & Within Groups & 937.75 & 139 & 6.74 & & \\
\hline & Total & 1162.65 & 144 & & & \\
\hline
\end{tabular}

Table 4. Transfer ANOVA results 


\subsection{Results of the Cognitive Load Measure}

Descriptive statistics for the cognitive load measure are displayed in Table 5. The results of the cognitive load measure, displayed in Table 6 and Figure 3, revealed a significant difference $F(5,139)=14.71, p<.001$, eta squared .35 . Tukey's post hoc analysis revealed that the $T O(M=5.44, S D=1.29)$ group scored significantly higher than the $T I(M=4.04 .26, S D=1.76), N I(M$ $=3.58, S D=1.76), T N I(M=3.61, S D=1.3)$, and $T I O(M=3.24, S D=1.61)$ groups. The $N O(M=6.22, S D=1.24)$ group scored significantly higher than the $T I(M=4.04 .26, S D=1.76), N I(M=3.58, S D=1.76), T N I(M=3.61, S D=1.3)$, and TIO $(M=3.24, S D$ $=1.61)$ groups. The $T I(M=4.04 .26, S D=1.76), N I(M=3.58, S D=1.76), T N I(M=3.61, S D=1.3)$, and $T I O(M=3.24, S D=1.61)$ groups did not significantly differ from one another. The $T O(M=5.44, S D=1.29)$ and $N O(M=6.22, S D=1.24)$ did not significantly differ from one another.

\begin{tabular}{|l|l|c|}
\hline & Mean & Standard Deviation \\
\hline Text Only $(T O)$ & 5.44 & 1.29 \\
\hline Narration Only $(N O)$ & 6.22 & 1.24 \\
\hline Text and Images $(T I)$ & 4.04 & 1.76 \\
\hline Narration and Images $(N I)$ & 3.58 & 1.76 \\
\hline Text and narration with images $(T N I)$ & 3.61 & 1.30 \\
\hline Text and Images with optional narration $(T I O)$ & 3.24 & 1.61 \\
\hline
\end{tabular}

Table 5. Descriptive statistics for cognitive load measure

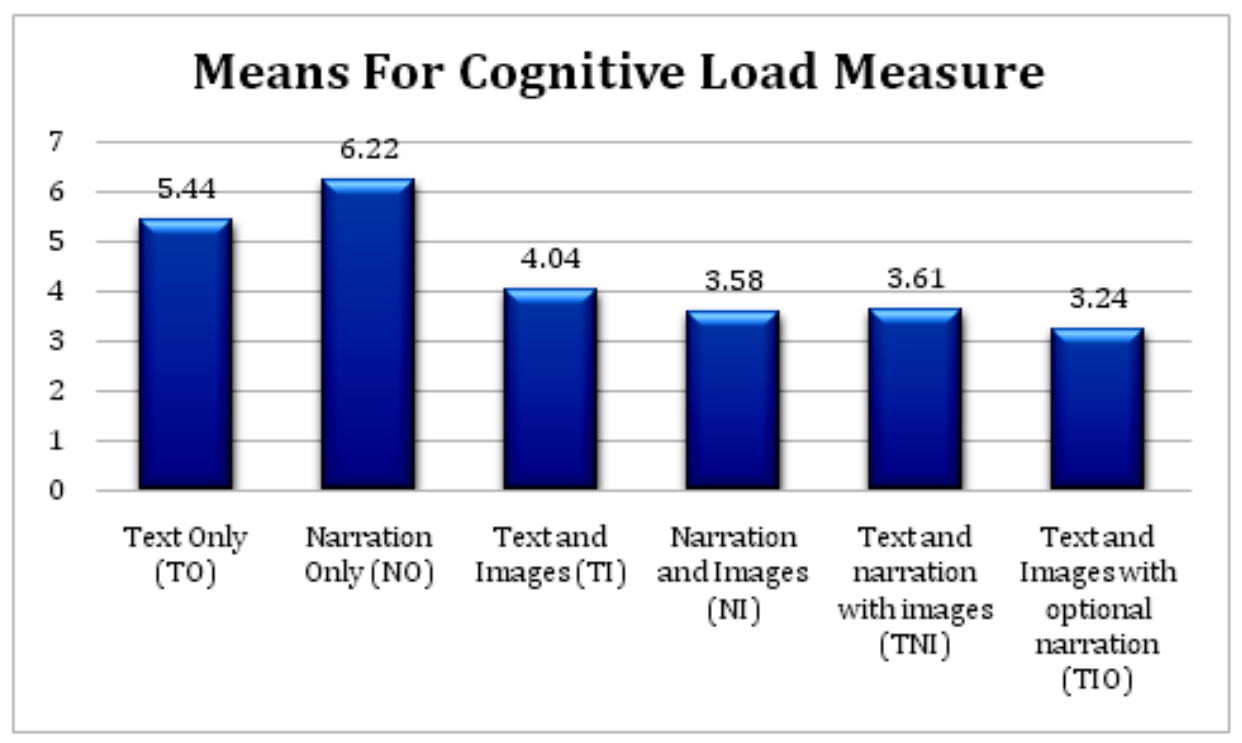

Figure 3. Means for Cognitive Load Measure

\begin{tabular}{|l|l|c|c|c|c|c|}
\hline & & Sum of Squares & df & Mean Square & $\boldsymbol{F}$ & Sig \\
\hline Cognitive Load & Between Groups & 169.85 & 5 & 33.97 & 14.71 & .000 \\
\hline & Within Groups & 320.91 & 139 & 2.31 & & \\
\hline & Total & 490.75 & 144 & & & \\
\hline
\end{tabular}

Table 6. Cognitive Load ANOVA results 
A visual of the means for the recall, transfer, and cognitive load measures are displayed in Figure 4.

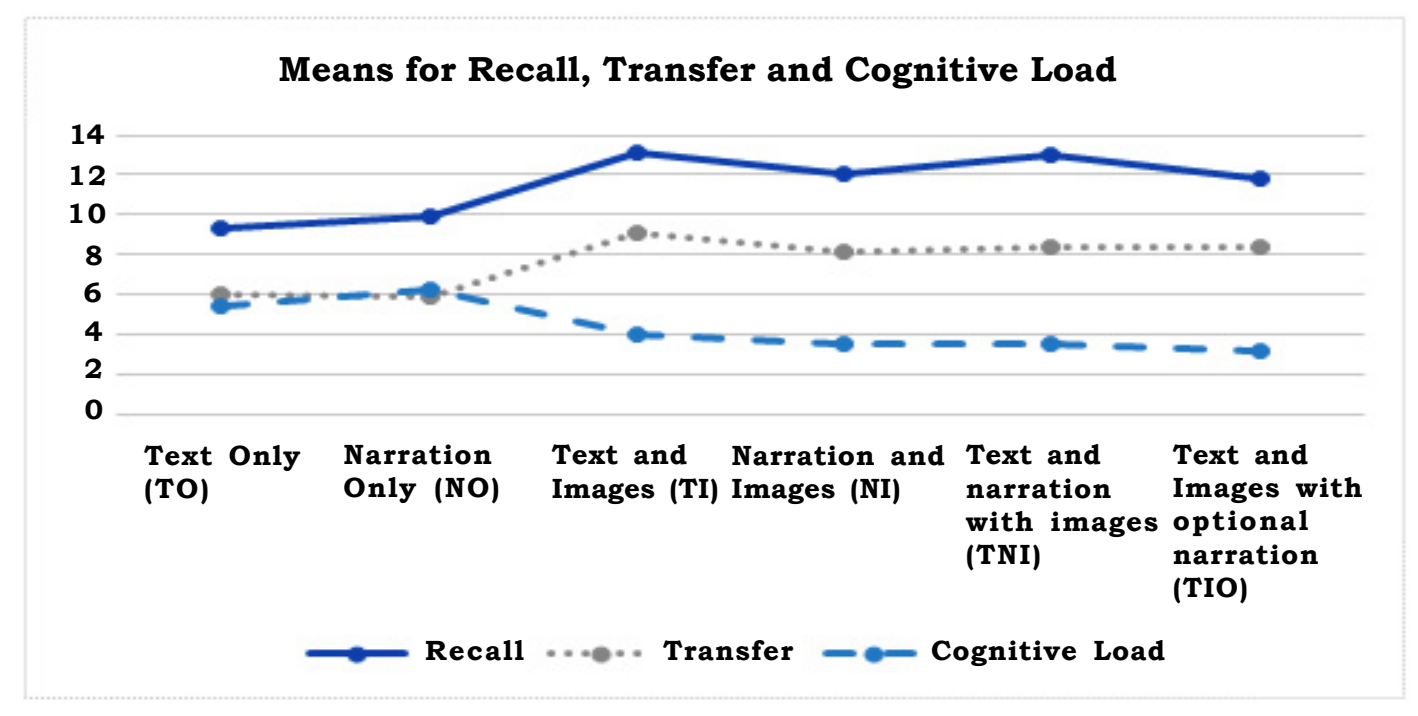

Figure 4. Means for Recall, Transfer, and Cognitive Load

\section{Discussion}

\subsection{Multimedia Principle}

The multimedia principle states that learning from multiple representations is better than learning from one (Clark \& Mayer, 2011). In this experiment, both single representation groups (TO and NO) performed significantly worse than all multiple representation groups for both recall and transfer measures (TI, NI, TNI, TIO). Additionally, participants felt through the selfreport cognitive load measure that the TO and NO groups caused more cognitive stress than all of the other groups. This decrease in performance and increase in cognitive load support Mayer and colleagues CTML (Mayer, 2005; 2014). The recall finding aligns with Pastore et al's (2016) meta-analysis indicating that multiple representations are better for recall learning than single representations. While Pastore et. al (2016) did not find a difference in transfer, they did find a medium-large effect size and noted that more studies were needed which measured high-level knowledge (transfer). As a result, the significant difference in transfer will help to add to a very small number of studies on the multimedia principle that focus on computer-based training with adult learners. The transfer finding is also inline with Mayer's research on the multimedia and helps to support the notion that multiple vs. single representations are better for learning high-level tasks than just one. Additionally, it is important to note that the single representation groups did not differ from another. This further emphasizes multiple representations over a single but also calls to researchers to examine strategies to improve learning when only a single representation is present.

\subsection{Modality Effect}

According to the modality effect, presenting learners with narration and images leads to higher levels of learning then presenting them with text and images (Sweller, Ayres, and Kalyuga, 2011). The results of this experiment did not find significant differences among groups for the recall, transfer, or cognitive load measures. In fact, participants scored higher on the TI group for both recall and transfer measure than the NI group, yet, they did report higher levels of cognitive load for the TI group. However, neither of those differences were significant. There are a few possible explanations as to why the modality principle did not hold true for this experiment. One possible explanation is that the information was well organized and chunked together. As a result, participants working memory was not overloaded on each slide when they had to go back and forth between the text and images providing an environment where the modality effect would have little impact on scores. This could indicate that there are design strategies to minimize the effects of representation holding and the modality effect. As a result, future research should explore strategies which could potentially minimize the effect of the modality principle.

\subsection{Redundancy Principle}

The redundancy principle states that presenting learners with redundant content, for example, text and duplicate narration, can inhibit learning (Kalyuga, Chandler, and Sweller 2014). This experiment not only tested the redundancy principle but provided 
learners an option to choose if they wanted duplicate narration or not. This experiment did not find significant results among any of the multiple representation groups for recall, transfer or the cognitive load measure. While not a significant difference, for both the recall and transfer measures, the TI group performed the best. This finding is not inline with Mayer and colleagues (2014) who found that redundant text and narration inhibit learning; however, the finding it inline with research on reverse redundancy (Leslie, Low, Jin, \& Sweller, 2012). What was most interesting was that the redundant groups slightly outperformed the NI group on the transfer measure. This was a case where redundancy really had no impact on learning. There are a few explanations for this finding. Each screen of instruction was well designed - short with one paragraph of text, so one explanation is that the screens were not long enough to elicit a redundancy effect. Another explanation was that participants might have listened/read but when the narration stopped, read the text again without replaying the audio narration. Good metacognitive skills may also of helped to overcome this phenomenon. More research, using tools like eye tracking, would help to delve deeper into this, specifically looking to see if principles like this apply when instruction is well designed, and learners have strong metacognitive skills. Additionally, participants reported the least amount of cognitive load on the TNO group. An explanation for this comes from Pastore's $(2014 ; 2016)$ learner preferences studies as learners prefer to have duplicate text and narration even though it may hinder their learning. Thus, they believe it's requiring less mental effort because they prefer it. As a result, more objective ways to determine cognitive load should be sought after.

\section{Conclusion}

The current study sought to confirm and expand prior research by examining the multimedia principle, the redundancy principle, and the modality principle in a computer-based environment on learning and cognitive load. Thus, this study helps to fill an important gap in the multimedia literature by examining single vs multiple representations as well as other multimedia principles on adults in a computer-based environment. The results of both the low (factual) and high (transfer) level learning tasks supported the multimedia principle. Multiple representations were found to be better for learning than just one. However, neither the modality or redundancy principles had an effect. Duplicate text and narration did not overwhelm learners working memory. Narration and image groups did not outperform text and image groups. Further research should continue to explore the multimedia principle in a computer-based environment along with other design and instructional strategies, specifically starting to test the effects of these principles in real environments. CBT is becoming very popular in academic, corporate, and government training and research on best design strategies is very much needed.

\section{References}

[1] Ackerman, P. L., Kanfer, R. (2009). Test length and cognitive fatigue: An empirical examination of effects on performance and test-taker reactions. Journal of Experimental Psychology: Applied, 15 (2) 163-181.

[2] Anmarkrud, O., Anderson, A., Braten, I. (2019). Cognitive load and working memory in multimedia learning: Conceptual and measurement issues. Educational Psychologist, 48 (3).

[3] Ari, F., Flores, R., Inan, F. A., Cheon, J., Crooks, S. M., Paniukov, D., Kurucay, M. (2014). The effects of verbally redundant information on student learning: An instance of reverse redundancy. Computers \& Education, 76, 199-204.

[4] Baddeley, A. D. (1998). Human memory: Theory and practice. Boston: Allyn and Bacon.

[5] Brunken, R., Plass, J. L., Leutner, D. (2003). Direct measurement of cognitive load in multimedia learning. Educational Psychologist, 38 (1) 53-61.

[6] Butcher, K. R. (2014). The multimedia principle. The Cambridge handbook of multimedia learning, 174-205.

[7] Chandler, P., Sweller, J. (1991). Cognitive load theory and the format of instruction. Cognition and Instruction, 8 (4) $293-332$.

[8] ChanLin, L. -J. (2001). Formats and prior knowledge on learning in a computer-based lesson. Journal of Computer-Assisted Learning, 17, 409e419.

[9] Chen, Cl., Yen, P. (2019). Learner control, segmenting, and modality effects in animated demonstrations used as the beforeclass instructions in the flipped classroom. Interactive Learning Environments.

[10] Clark, R. C., Mayer, R. E. (2011). Applying the Multimedia Principle: Use Words and Graphics Rather Than Words Alone. $e$ Learning and the Science of Instruction: Proven Guidelines for Consumers and Designers of Multimedia Learning, Third Edition, 66-89.

$58 \quad$ Journal of Multimedia Processing and Technologies Volume 10 Number 2 June 2019 
[11] Cooper, G. (1998). Research into cognitive load theory and instructional design at UNSW. Sydney: University of New South Wales.

[12] de Koning, B. B., van Hooijdonk, C. M. J., Lagerwerf, L. (2017). Verbal redundancy in a procedural animation: On-screen labels improve retention but not behavioral performance, Computers \& Education, doi: 10.1016/j.compedu.2016.12.013.

[13] Dwyer, F. M. (1965). An experimental evaluation of the relative effectiveness of selected visual illustrations in teaching science concepts to college freshmen. Unpublished Dissertation. The Pennsylvania State University, University Park, PA.

[14] Dwyer, F. M. (1972). A guide for improving visual instruction. Learning services, box 784. PA: State College.

[15] Dwyer, F. M. (1978). Strategies for improving visual learning. Learning services, box 784. PA: State College.

[16] Dwyer, F. M., Lamberski, R. (1983). The instructional effect of coding (color and black and white) in facilitating students' information acquisition and retrieval. Educational Communication \& Technology Journal, 31, 9-21.

[17] Eitel, A., Scheiter, K., Schuler, A. (2013). How inspecting a picture affects processing of text in multimedia learning. Applied Cognitive Psychology, 27, 451-461.

[18] Fiorella, L., Vogel-Walcutt, J., Schatz, S. (2012). Applying the modality principle to real-time feedback and the acquisition of higher-order cognitive skills. Educational Technology Research and Development, 60 (2) 223-238.

[19] Florax, M., Ploetzner, R. (2010). What Contributes to the Split-Attention Effect? The Role of Text Segmentation, Picture Labeling, and Spatial Proximaty. Learning and Instruction, 20, 216-224.

[20] Ginns, P. (2006). Integrating information: A meta-analysis of the spatial contiguity and temporal contiguity effects. Learning and Instruction, 16, 511-525.

[21] Hegarty, M., Just, M. A. (1993). Constructing mental models of machines from text and diagrams. Journal of Memory and Language, 32 (6) 717-742.

[22] Gunawardhana, L. K., Palaniappan, S. (2016). Possibility of using multimedia application for learning. Journal of Computing, $5(1) 77-83$.

[23] Hoekstra, R., Kiers, H., Johnson, A. (2012). Are assumptions of well-known statistical techniques checked, and why (not)?. Frontiers in Psychology, 3 (137).

[24] Issa, N., Schuller, M., Santacaterina, S., Shapiro, M., Wang, E., Mayer, R. E., DaRosa, D. A. (2011). Applying multimedia design principles enhances learning in medical education. Medical Education, 45 (8) 818-826.

[25] Kalyuga, S., Chandler, P., Sweller, J. (1999). Managing split-attention and redundancy in multimedia instruction. Applied Cognitive Psychology, 13, 351-371.

[26] Kalyuga, S., Chandler, P., Sweller, J. (2004). When Redundant On-Screen Text in Multimedia Technical Instruction Can Interfere With Learning. Human Factors, 46 (3) 567-581.

[27] Kamaruddin, N., Sulaiman, S. (2018). Understanding interface design principles and elements guidelines: A content analysis of established scholars. In: Proceedings of the art and design international conference.

[28] Leslie, K. C., Low, R., Jin, P., Sweller, J. (2012). Redundancy and expertise reversal effects when using educational technology to learn primary school science. Educational Technology Research and Development, 60 (1) 1-13.

[29] Low, R., Sweller, J. (2005). The modality principle in multimedia learning. In: R. Mayer (Ed.), The Cambridge handbook of multimedia (p. 147-158). NY: Cambridge University Press.

[30] Mahdi, Z., Naidu, V., Kurian, P. (2019). Analyzing the role of human computer interaction principles for e-learning in solution design. Smart Technology and Innovation for a Sustainable Future. 41-44.

[31] Mayer, R., Anderson, R. (1992). The instructive animation: Helping students build connections between words and pictures in multimedia learning. Journal of Educational Psychology, 84, 444-452.

[32] Mayer, R. E., Bove, W., Bryman, A., Mars, R., Tapangco, L. (1996). When less is more: Meaningful learning from visual and verbal summaries of science textbook lessons. Journal of Educational Psychology, 88, 64-73.

[33] Mayer, R. E. (2001). Multimedia learning. New York: Cambridge University Press.

[34] Mayer, R. E. (2002). Multimedia learning. In: The Annual Report of Educational Psychology in Japan, 41, 22-29.

Journal of Multimedia Processing and Technologies Volume 10 Number 2 June 2019 
[35] Mayer, R., Heiser, J., Lonn, S. (2001). Cognitive constraints on multimedia learning: When presenting more material results in less understanding. Journal of Educational Psychology, 93, 187-198. doi:10.1037/0022-0663.93.1.187.

[36] Mayer, R. E., Johnson, C. I. (2008). Revising the redundancy principle in multimedia learning. Journal of Educational Psychology, 100 (2) 380.

[37] Mayer, R., Chandler, P. (2001). When learning is just a click away: Does simple user interaction foster deeper understanding of multimedia messages? Journal of Educational Psychology, 93 (2) 390-397.

[38] Mayer, R. E., Moreno, R. (2003). Nine ways to reduce cognitive load in multimedia learning. Educational Psychologist, 38 (1) 43-52.

[39] Mayer, R. E. (2005). Introduction to multimedia learning. In: R. Mayer (Ed.), The Cambridge handbook of multimedia (p. 116). NY: Cambridge University Press.

[40] Mayer, R. E. (2009). Multimedia learning (2nd ed). New York: Cambridge University Press.

[41] Mayer, R. E. (2014). The Cambridge handbook of multimedia learning. New York: Cambridge University Press.

[42] McAlpin, E., Kalaycioglu, S., Shilane, D. (2019). Dynamic Versus Static Presentation Formats, Do They Impact Performance Differently? Journal of Computers in Mathematics and Science Teaching, 38 (1) 49-76.

[43] Miller, G. A. (1956). The magical number seven, plus or minus two: some limits on our capacity for processing information. Psychological Review, 63 (2) 81-97.

[44] Moreno, R., Mayer, R. E. (2002). Learning science in virtual reality multimedia environments: Role of methods and media. Journal of Educational Psychology, 94, 598- 610.

[45] Moreno, R., Mayer, R. E. (2002). Verbal redundancy in multimedia learning: When reading helps listening. Journal of Educational Psychology, 94 (1) 156-163.

[46] Nagmoti, J. M. (2017). Departing from PowerPoint default mode: Applying Mayer's multimedia principles for enhanced learning of parasitology. Indian Journal of Medical Microbiology, 35 (2), 199.

[47] Paas, Fred., Tuovinen, Juhani., Tabbers, Huib., Van Gerven, Pascal. (2003). Cognitive Load Measurement as a Means to Advance Cognitive Load Theory. Educational Psychologist - EDUC PSYCHOL. 38. 63-71.10.1207/S15326985EP3801_8.

[48] Packer, R., Jordan, K. (Eds.). (2002). Multimedia: from Wagner to virtual reality. WW Norton \& Company.

[49] Paivio, A. (1986). Mental representations. New York: Oxford University Press.

[50] Pastore, R. (2010). The effects of diagrams and time-compressed instruction on learning and learners' perceptions of cognitive load. Education Technology and Research Development, 58, 485-505.

[51] Pastore, R. (2012). The effects of time - compressed instruction and redundancy on learning and learners' perceptions of cognitive load. Computers \& Education, 58 (1) 641-651.

[52] Pastore, R. (2016). Learner preferences in multimedia design. Journal of Multimedia Processing and Technologies, 7 (4) $144-152$.

[53] Pastore, R. (2014). Multimedia: Learner Preferences For Multimedia Learning. Journal of Multimedia Processing and Technologies, 5 (4) 134-144.

[54] Pastore, R., Briskin, J., Asino, T. (2016). The multimedia principle: A meta-analysis. International Journal of Instructional Technology and Distance Learning. 13 (11) 17-30.

[55] Pollock, E., Chandler, P., Sweller, J. (2002). Assimilating complex information. Learning and Instruction, 12, 61-86.

[56] Rogers, E. M. (2010). Diffusion of innovations. Simon and Schuster.

[57] Samur, Y. (2012). Redundancy effect on retention of vocabulary words using multimedia presentation. British Journal of Educational Technology, 43(6).

[58] Scheiter, K., Schuler, A., Gerjets, P., Huk, T., Hesse, F. W. (2014). Extending multimedia research: How do prerequisite knowledge and reading comprehension affect learning from text and pictures. Computers in Human Behavior, 31, 73-84.

[59] Sorden, S. D. (2005). A cognitive approach to instructional design for multimedia learning. Informing Science, 8.

$60 \quad$ Journal of Multimedia Processing and Technologies Volume 10 Number 2 June 2019 
[60] Sweller, J., van Merrienboer, J. J. G., Paas, F. (1998). Cognitive architecture and instructional design. Educational Psychology Review, 10, 251-296.

[61] Sweller, J. (1988). Cognitive load during problem solving: Effects on learning. Cognitive Science, 12 (2) 257-285.

[62] Sweller, J. (1994). Cognitive load theory, learning difficulty, and instructional design. Learning and instruction, 4 (4) 295312.

[63] Sweller, J. (1999). Instructional design in technological areas. Camberwell, Australia: ACER Press.

[64] Sweller, J. (2005). The redundancy principle. In: R. Mayer (Ed.), Cambridge handbook of multimedia learning (p. 147-158). New York: Cambridge University Press.

[65] Sweller, Ayres., Kalyuga. (2011). Cognitive load theory. Springer, New York, NY.

[66] Toh, S. C., Munassar, W. A. S., Yahaya, W. A. (2010). Redundancy effect in multimedia learning: A closer look. C. Steel, M. J. Keppell, P. Gerbic, \& S. Housego, Curriculum, Technology \& Transformation for an unknown Future, 988-998.

[67] Rapchak, M. E. (2017). Is Your Tutorial Pretty or Pretty Useless? Creating Effective Tutorials with the Principles of Multimedia Learning. Journal of Library \& Information Services in Distance Learning, 11(1-2), 68-76.

[68] Reyna, J., Hanham, J., Meier, P. (2018). The internet explosion, digital media principles and implications to communicate effectively in the digital space. E-Learning and Digital Media, 15(1).

[69] Sung, E., Mayer, R. E. (2012). When graphics improve liking but not learning from online lessons. Computers in Human Behavior, 28 (5) 1618-1625.

[70] Tabbers, H. K., Martens, R., Van Merriënboer, J. J. G. (2000). Multimedia instructions and cognitive load theory: Splitattention and modality effects. In: National Convention of the Association for Educational Communications and Technology, Long Beach, $C A$.

[71] Vaughan, T. (2011). Multimedia: Making it work, 8th ed., New York, NY: McGraw-Hill Osborne Media.

[72] Yue, C. L., Bjork, E. L., Bjork, R. A. (2013). Reducing verbal redundancy in multimedia learning: An undesired difficulty? Journal of Educational Psychology, 105 (2) 266-277. 